\title{
Treatment of bisphosphonate related osteonecrosis following root canal therapy at the I-year follow-up: report of two cases
}

This article was published in the following Dove Press journal:

Therapeutics and Clinical Risk Management

29 November 2013

Number of times this article has been viewed

\author{
Figen Kaptan' \\ Meric Karapinar Kazandag' \\ Ufuk Iseri ${ }^{2}$ \\ 'Yeditepe University, Faculty \\ of Dentistry, Department of \\ Endodontics, ${ }^{2}$ Department of \\ Prosthodontics, Istanbul, Turkey
}

Correspondence: Meric Karapinar Kazandag

Yeditepe University, Faculty of Dentistry, Department of Endodontics, Bağdat cad

No 238 Goztepe, 34728, Istanbul, Turkey

Tel +905326473469

Email mkarapinar@yahoo.com

\begin{abstract}
The objective of this report was to use topical gaseous ozone as an adjunct to conventional treatment methods and to describe the multidisciplinary management of bisphosphonate associated bone necrosis, which developed following endodontic treatment. No complaints were noted by the patients at their 1-year follow-up and the treatment showed favorable prognosis.
\end{abstract}

Keywords: bisphosphonate, osteonecrosis, BRONJ, endodontics, oxygen, ozone

\section{Introduction}

Bisphosphonates are drugs that affect bone turnover and have been used in the treatment of several conditions related to the skeleton system since the start of the 2000s. ${ }^{1}$ Less potent bisphosphonates, such as alendronate and risedronate, are administered orally to control non-malignant bone disorders such as osteoporosis and Paget's disease, whereas the more potent nitrogen containing intravenous bisphosphonates are favored to prevent skeletal disorders associated with malignancy and severe forms of osteogenesis imperfecta. ${ }^{2}$

Bisphosphonate related osteonecrosis of the jaw (BRONJ) is a known complication of these drugs, first reported in 2003 and described as "a condition of an area of exposed bone in the maxillofacial region accompanied with pain". ${ }^{3}$ Ruggiero et al described Stages 1-3 as well as risk categories in $2006^{4}$ and added a Stage 0 in 2009 (Table 1).

Reducing the risk depends on awareness and avoiding predisposing factors for BRONJ. A number of risk factors for BRONJ have been determined from longitudinal follow-up of cohorts taking bisphosphonates, ${ }^{2}$ although a significant number of patients develop spontaneous BRONJ. ${ }^{5}$ The most common risk factors are dental procedures causing trauma in the dentoalveolar bone as well as dosage and duration of bisphosphonates treatment. A majority of the patients were reported to have a history of dental procedures, such as tooth extractions, periodontal surgery, and root canal treatment with rates of $49.1 \%, 27.1 \%$, and $1.7 \%$, respectively. ${ }^{6}$ Root canal treatment serves as a treatment alternative to tooth extraction and lowers the possibility of this treatment modality to cause BRONJ.

The American Association of Oral and Maxillofacial Surgeons (AAOMS) added a new category to staging in 2009. The name of this new category was Stage 0 and represents patients with "non-specific clinical findings and symptoms such as jaw pain or osteosclerosis but no clinical evidence of exposed bone". ${ }^{1}$ Greater than $50 \%$ of the patients at Stage 0 develop exposed bone at painful sites within 5-8 months; $;, 6$ however, complete mucosal closure cannot be achieved for more than $50 \%$ of these patients. ${ }^{6}$ Bone 
Table I Classification of patients using bisphosphonates based on BRONJ

\begin{tabular}{|c|c|}
\hline At risk category & $\begin{array}{l}\text { No apparent exposed/necrotic bone in patients } \\
\text { who have been treated with either oral or IV } \\
\text { bisphosphonates }\end{array}$ \\
\hline Stage 0 & $\begin{array}{l}\text { Non-specific clinical findings and symptoms such as } \\
\text { jaw pain or osteosclerosis but no clinical evidence } \\
\text { of exposed bone }\end{array}$ \\
\hline Stage I & $\begin{array}{l}\text { Exposed/necrotic bone in patients who are } \\
\text { asymptomatic and have no evidence of infection }\end{array}$ \\
\hline Stage 2 & $\begin{array}{l}\text { Exposed/necrotic bone associated with infection as } \\
\text { evidenced by pain and erythema in the region of the } \\
\text { exposed bone with or without purulent drainage }\end{array}$ \\
\hline Stage 3 & $\begin{array}{l}\text { Exposed/necrotic bone in patients with pain, } \\
\text { infection, and one or more of the following: } \\
\text { pathologic fracture, extraoral fistula, or osteolysis } \\
\text { extending to the inferior border or sinus floor }\end{array}$ \\
\hline
\end{tabular}

Notes: Copyright (C) 2006, with permission from Elsevier. Reproduced from Ruggiero SL, Fantasia J, Carlson E. Bisphosphonate-related osteonecrosis of the jaw: background and guidelines for diagnosis, staging and management. Oral Surg Oral Med Oral Pathol Oral Radiol Endod. 2006; I02(4):433-44I. ${ }^{4}$ Copyright (C) 2009. With permission from Elsevier. Reproduced from Ruggiero SL, Dodson TB, Assael LA, Landesberg R, Marx RE, Mehrotra B; American Association of Oral and Maxillofacial Surgeons. American Association of Oral and Maxillofacial Surgeons position paper on bisphosphonate-related osteonecrosis of the jaws - 2009 update. J Oral Maxillofac Surg. 2009;67(Suppl 5):2-12.'

Abbreviations: BRONJ, bisphosphonate related osteonecrosis of the jaw; IV, intravenous.

scintigraphy is a routine tool used by oncologists to monitor some cancer types. Although nuclear imaging has limited value in patients with existing disease, ${ }^{7}$ its usefulness ${ }^{6,8}$ as a predictive tool for patients at Stage 0 seems to have some level of potential benefit $^{9}$ and therefore requires continued evaluation.

Treatment strategies suggested for patients at Stage 0 are to provide symptomatic treatment, and conservatively manage other local factors, such as caries and periodontal disease. ${ }^{1}$ Systemic management may include the use of medication for chronic pain and control of infection with antibiotics, when indicated. ${ }^{1}$

Various forms of oxygen are used for disinfecting and therapeutic purposes. There is emerging evidence that suggests hyperbaric oxygen treatment improves the prognosis of BRONJ. ${ }^{10}$ Ozone is a naturally occurring compound that consists of three oxygen atoms. Ozone is biocompatible, ${ }^{11}$ affects oral microorganisms, ${ }^{12,13}$ and has no known side effects ${ }^{14}$ on cells when used in appropriate concentrations, making ozone therapy a potential adjunct to conventional therapies for BRONJ patients in addition to conventional therapies. ${ }^{15}$ However, the instability of the aqueous form of ozone, the toxicity of the gaseous form of ozone, and the inability of the oil form of ozone to not washout with saliva makes the usage of ozone impractical for intraoral applications. A recently marketed ozone generator enables a clinician to apply gaseous ozone topically onto a wound without risk of inhalation and is promising for dental purposes.
The current report presents the treatment of two BRONJ cases at Stage 0, occurring after root canal treatment, using topical gaseous ozone in addition to conventional therapy.

\section{Case I}

A 64-year-old female patient was referred to the Yeditepe University, Faculty of Dentistry with a complaint of severe pain in the right mandible. Her medical history revealed that she was diagnosed with breast cancer 4 years previously, originating from the right breast. Her treatment consisted of nine sessions of chemotherapy, followed by intravenous (IV) zoledronic acid (Zometa ${ }^{\circledR}$, Novartis, Surrey, UK) once a month for 4 years. The patient's current medications included IV Zometa ${ }^{\circledR}$ and fulvestrant (Faslodex ${ }^{\circledR}$, AstraZeneca, London, UK). During the clinical and radiographical examination, decayed dentine was detected distal to the crown of tooth \#46 (Figure 1A). The bridge restoration using teeth \#44 and \#46 as abutments was removed. During removal of the carious dentine, pulp tissue was exposed. Rubber dam was applied following endodontic cavity preparation. The root canal orifices were located with an endodontic explorer (DG 16, Sybron Endo, Orange, CA, USA). The working lengths were measured with an apex locator (Apexit, Micro Mega, Besancon, France) in addition to periapical radiographs. The root canals were shaped with rotary instruments (Revo-S, Micro Mega) until an apical diameter of \#30 (Revo-S, AS30, Micro Mega) and a taper of 0.06 were achieved. The root canal

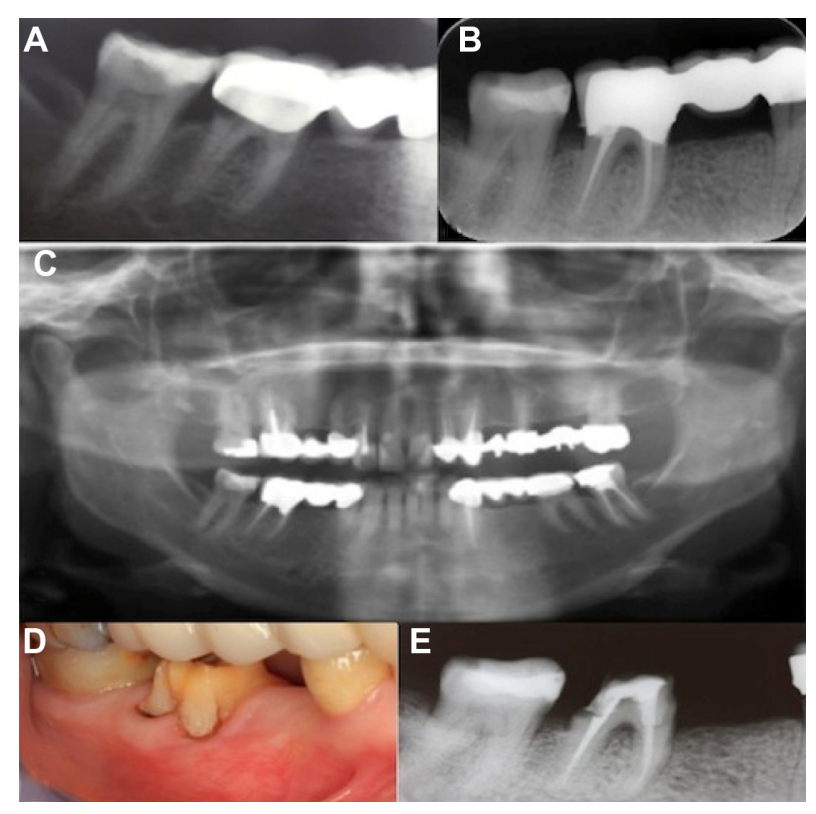

Figure I (A) Preoperative radiograph of tooth \#46. (B) Postoperative radiograph following root canal treatment. (C) Panaromic radiography following bridge restoration. (D and $\mathbf{E})$ Intraoral appearance and periapical radiograph at I-year recall. 
irrigation was performed with $2 \mathrm{~mL}$ of $5 \% \mathrm{NaOCl}$ following each instrument. The final irrigation was performed with $10 \mathrm{~mL}$ of $5 \% \mathrm{NaOCl}$ followed by $10 \mathrm{~mL}$ ethylenediaminetetraacetic acid (EDTA) and $10 \mathrm{~mL}$ deionized water. Irrigation was delivered with 0.19 inch capillary tips (Ultradent, South Jordan, UT, USA) at 2 to $4 \mathrm{~mm}$ from the root tip. The root canals were obturated with gutta percha (Diadent; Diadent Group, International, Burnaby, BC, Canada) and a resin based sealer (Ah-Plus; Dentsply, Maillefer, Switzerland) by lateral condensation. Endodontic treatment was completed in the same session (Figure 1B). Following root canal therapy, the related teeth were restored with fixed bridge restoration (Figure 1C). All dental procedures were performed under antibiotic prophylaxis ( $2 \mathrm{~g}$ amoxicillin, 1 hour before the procedure) upon a consultation with the patient's oncologist.

The patient presented with pain and purulent drainage in the mandibular right jaw 2 months after the initial treatment. A bone scintigraphy taken a few days prior was available at the time of the dental visit. A radiolucent area corresponding to the painful area was detected on the scintigraphy and had already been marked by the radiologist (Figure 2). Upon clinical examination, none of the teeth were tender to percussion and palpation, an insufficient amount of keratinized gingival tissue due to recession was found, as well as a $6 \mathrm{~mm}$ pocket depth measured on the buccal side of the mesial root surface of tooth \#46. Scaling and root planning were gently performed to not cause any trauma in the related area. The fixed prosthetic restoration was removed to check any irritation and recemented. The patient was also prescribed $1 \mathrm{~g}$ of amoxicillin three times a day for 1 week to control the infection. At the second appointment, no change was observed in terms of pocket depth, purulent drainage, of pain level compared to

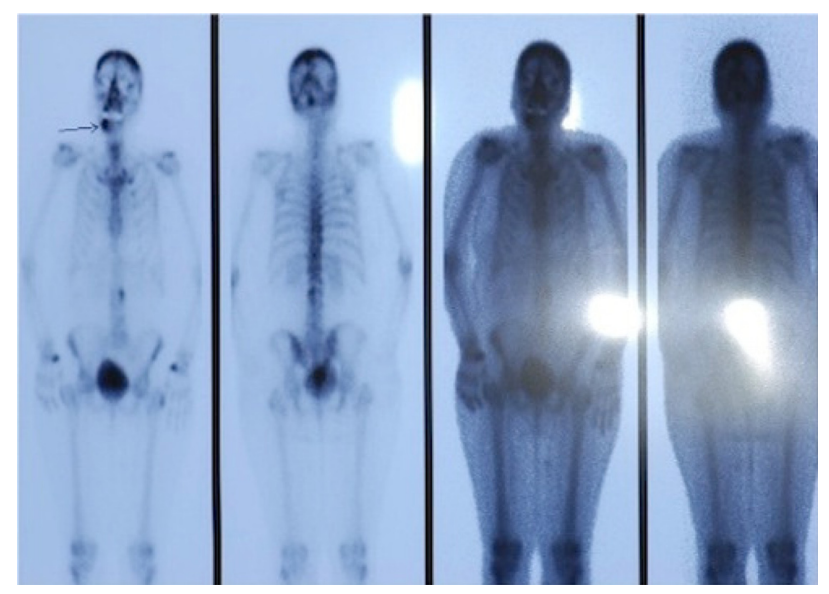

Figure 2 Bone scintigraphy taken 2 months after root canal treatment. Notes: A radioluscent area indicating a pathology in the right mandibular jaw was marked by radiologist (arrow). the first session. Topical gaseous ozone was applied using an Omega Probe (Biozonix, Munich, Germany) at the highest level (level 5). This application was made extraorally through the gel (provided with probe) applied onto skin through the buccal side, three times a week for 10 minutes and a total of 12 sessions as an adjunct to an antibiotic regimen with clindamycin (150 mg Cleocin ${ }^{\circledR}$, Eczacıbaşı Holding, Istanbul, Turkey), four times a day for 1 week. At the end of the 4 weeks, the pain and drainage had disappeared, the pocket depth was reduced to $5 \mathrm{~mm}$ and the infection was eliminated; although a complete reversal was not achieved.

The patient was educated on all symptoms of BRONJ and was recommended to return to the dental clinic in case of any of the BRONJ symptoms recurred. The patient was free of any clinical symptoms, periodontal status and radiolucent lesions and was stable at a 1-year recall (Figure 1D and 1E).

\section{Case 2}

A 62-year-old female patient presented to the Yeditepe University, Faculty of Dentistry with prosthetic needs (Figure 3A). Her medical history revealed a diagnosis of breast cancer and oral bisphosphonate administration (Fasamax, Merck, Whitehouse Station, NJ, USA) $5 \mathrm{mg}$ per day along with anastrozole (Arimidex ${ }^{\circledR}$, AstraZeneca) $1 \mathrm{mg}$ per day for 4 years. Root canal treatments were performed as described above for teeth \#35, \#45, and \#47 due to prosthetic reasons and two implants were placed to replace missing teeth \#36 and \#37 (Figure 3B and C). The tooth \#47 did not have $\mathrm{C}$ canal

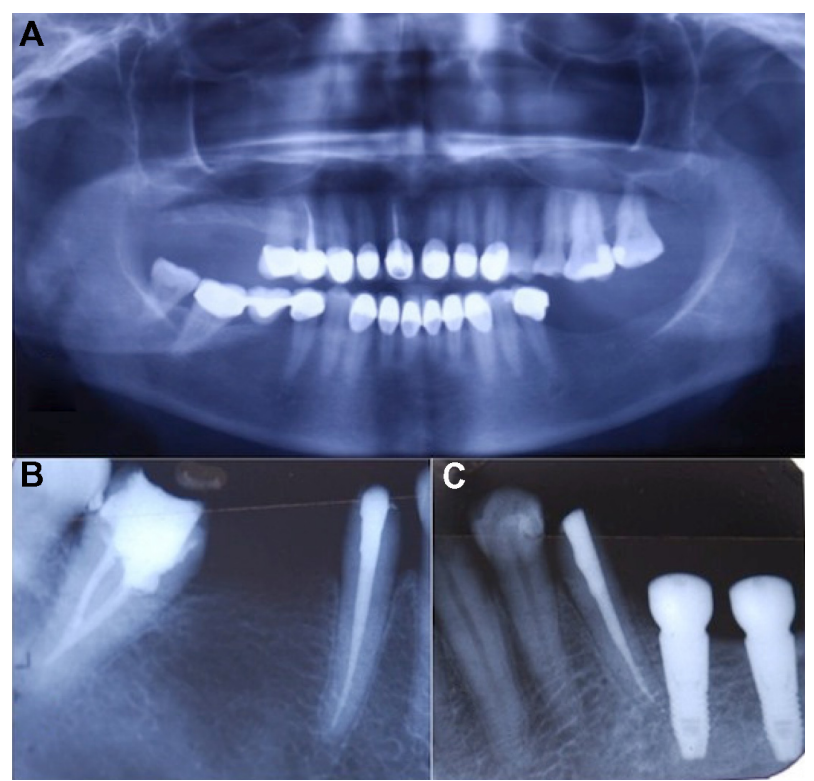

Figure 3 (A) Preoperative panoramic radiography. (B) Root canal treated teeth \#45 and \#47. (C) Root canal treatment of tooth \#35 and two implants placed to replace missing teeth \#36 and \#37. 
configuration. Extreme care was taken to provide oral hygiene during that period and prophylactic antibiotics ( $2 \mathrm{~g}$ of amoxicillin 1 hour before treatment) was also administered for each session. One month later, the patient complained of a mild pain in the dentoalveolar bone of the right mandible. None of the teeth were tender to percussion and palpation. Antibiotics were prescribed (500 $\mathrm{mg}$ amoxicillin three times a day for 3 weeks) and topical ozone treatment was initiated, as described above. The patient was trained to detect symptoms of BRONJ as described above and scheduled for regular dental monitoring on a 6 month basis.

The intravenous administration of zoledronic acid ( $4 \mathrm{mg}$ Zometa $^{\circledR}$, Novartis) every 6 months was initiated upon a diagnosis of progression of breast cancer approximately 1 month after the endodontic therapy. At the 1-year recall, no symptoms related to BRONJ were present.

\section{Discussion}

Bisphosphonates are used, despite some potential complications, ${ }^{2}$ on patients to improve the life quality of cancer patients ${ }^{1}$ and reduce the risk of hip and vertebral fracture in patients with osteoporosis. ${ }^{16}$

BRONJ is a known complication refractory to treatment, with an incidence of $0.8 \%-12 \% .{ }^{1}$ Every single effort to improve the prognosis of BRONJ deserves attention, especially when considering the fact that over 190 million $^{1}$ oral bisphosphonate prescriptions have been dispensed worldwide.

One quarter ${ }^{6}$ to one half ${ }^{10}$ of BRONJ patients with bone exposure seem to benefit from BRONJ treatment. However, $43 \%$ of these patients demonstrate recurrence. Recurrent bone exposure, pain, and signs of infection are observed in these patients over the long term. ${ }^{6}$

Since the treatment of osteonecrosis is very difficult, protective and preventive interventions must be given priority. It is essential to take a proper and careful medical history in adults, specifically if they have undergone treatment for osteoporosis or cancer. A number of risk factors for BRONJ have been ascertained from longitudinal follow-up studies of cohorts taking bisphosphonates. ${ }^{2}$ Risk factors that have been demonstrated to be statistically significant include: type of cancer, ${ }^{17}$ duration of bisphosphonate exposure, ${ }^{17-20}$ number of infusions, ${ }^{20,21}$ the use of zoledronic acid, ${ }^{18,21}$ cyclophosphamide therapy, ${ }^{19}$ prednisone therapy, ${ }^{19}$ erythropoietin therapy, ${ }^{19}$ low hemoglobin levels, ${ }^{19}$ renal dialysis, ${ }^{19}$ osteoporosis, ${ }^{20}$ advanced age, ${ }^{19}$ and dental extractions. ${ }^{19,20}$ Although the majority of BRONJ cases have a history of IV administration of bisphosphonates, oral forms are not sideeffect free, ${ }^{22}$ especially when they are used for more than
3 years. ${ }^{1}$ The first case in the current study had a high risk due to a history of long-term IV zoledronic acid usage; whereas, the second case was reported to have used oral zoledronic acid for 4 years. Advanced age is another risk factor that was common for both cases. The authors do recognize that other restorative treatment modalities that do not require surgical intervention would be less risky compared to placing implants for an elderly patient on a long term bisphosphonate therapy as was presented in Case 2.

Therefore, the correction and maintenance of oral hygiene, fluoride application, and all invasive procedures, including extractions, should be completed prior to bisphosphonate treatment to reduce the risk of developing BRONJ. Splinting is done if there is a degree of mobility of 1 or 2 . If mobility is 3 , the risk of osteonecrosis is high. ${ }^{3,23}$ The patients presented above did not visit the dental clinic before the initiation of bisphosphonate therapy. For this reason, the attempts of the current authors to prevent bone exposure were restricted to not causing any trauma on the alveolar bone and root canal treatment was preferred over tooth extraction. The irrigation and shaping procedures were performed based on working lengths calculated with an apex locator utilized in addition to periapical radiography to make precise measurements and avoid over instrumentation. The working lengths were calculated based on apex locator measurements rather than radiographic findings considering the possibility of recession of the apical foramen due to secondary dentin and cement accumulation in elderly patients.

According to the AAOMS statement, patients may have BRONJ if all of the following three characteristics are present: 1) current or previous treatment with a bisphosphonate; 2) exposed bone in the maxillofacial region that has persisted for more than 8 weeks; and 3) no history of radiation therapy to the jaws. Neither of the current patients had exposed bone, which was contrary to the disease's definition; however, both patients were diagnosed as BRONJ at Stage 0 as pain in the dentoalveolar bone is accepted to be the most frequent factor $(83 \%)^{6}$ of early symptoms and a significant number of patients can have BRONJ without obvious bone exposure. ${ }^{5}$ It is possible that the trigger may be pulpal and/or periodontal as well as spontaneous. The authors of the present paper recognize that the root canal therapy may not be the cause; however, the pain was observed following endodontic treatment.

A bone scintigraphy was helpful for the differential diagnosis of the patient presented in Case 1. Neither an extra tool for differential diagnosis nor any symptoms other than pain were available for Case 2. However, when considering the possibility 
of pain as the only sign for Stage 0 BRONJ and a history of dental procedures during bisphosphonate therapy, a treatment strategy similar to Case 1 was followed for Case 2.

Amoxicillin was preferred for both cases, as most of the isolated microbes in BRONJ are sensitive to the penicillin group of antibiotics. Quinolones, metronidazole, clindamycin, doxycycline, and erythromycin have been used with success in patients who are allergic to penicillin. The present authors recognize the potential benefits of choosing an antibiotic in accordance with a microbial culture for Case 1, where amoxicillin did not work. On the other hand, antibiotic usage can be questionable for Case 2 , where the only symptom was pain and no other signs of infection existed.

Hyperbaric oxygen treatment seems to improve the prognosis of BRONJ. ${ }^{10}$ Although an aforementioned study could not reach adequate power due to the unstable condition of the study cohort, the positive effect can be attributed to increased tissue regeneration, ${ }^{24,25}$ vasculogenesis, ${ }^{26,27}$ and wound healing, ${ }^{22,27}$ while also providing reliable antimicrobial effects. ${ }^{12,13}$ The use of ozone, another type of oxygen therapy described above, in combination with antibiotics and surgery for patients with exposed bone lesions was also subject to clinical investigation and found to work to resolve pain, secretions, and halitosis. ${ }^{28}$ The type of ozone utilized in that previous study was not clear and the level of evidence is restricted to the case series, as neither a control group nor any statistical analysis was reported. There is, however, evidence for the biocompatibility ${ }^{11,14}$ and antimicrobial effects $^{12,13}$ of ozone in the present study. In Case 1, ozone and conventional root planning and scaling therapy might have contributed to reducing the periodontal pocket depth by reducing the bacterial count. ${ }^{29}$ The authors of the present paper recognize that there is insufficient evidence ${ }^{30}$ for some of the previously attributed effects of ozone, ${ }^{31}$ such as induction of immunostimulation, biosynthesis, vasodilatation, angiogenesis, and preventing hypoxia; however, there is no evidence to the contrary, either. Therefore, the patient in Case 2 might have benefited from any of these biologic properties. Additionally, the topical gaseous form of ozone utilized in the current cases is fairly new and has yet to be investigated from all aspects, including biological effects. This new method has all of the potential benefits of ozone therapy and lacks the disadvantages of aqueous, gaseous, and oil forms of ozone that are described above. There is no established criterion for using this device on such cases. Therefore, we have chosen the highest dose to begin somewhere. Further studies are necessary to find out which dose would work best for patients.
The current authors found the ozone generator to be very practical, not only with regards to the tip design, which makes it suitable for intraoral use, but also the device itself is easy to carry in a small handbag. This enables the dentist to continue the treatment on a patient who cannot visit (ie, hospitalized) the dental office. This aspect of the generator is very important, as ozone therapy requires daily use for a prolonged period of time.

Regular monitoring of patients was scheduled for the two patients in the current cases on a 6 month basis, with an emphasis on tendency for recurrence ${ }^{6}$ of the disease.

Only a few cases have been reported that relate osteonecrosis of endodontic origin. ${ }^{6,32}$ The current cases serve as the first on which ozone was used as an adjunct to conventional treatment for the treatment of BRONJ at Stage 0 following endodontic treatment.

\section{Conclusion and summary}

Within the limitations of the present case reports, the use of topical gaseous ozone may serve as a good option for treating BRONJ due to its favorable outcomes and no recurrence during a follow-up time of 1 year. However, randomized clinical studies are necessary to reach valid conclusions.

\section{Disclosure}

The authors report no conflicts of interest in this work.

\section{References}

1. Ruggiero SL, Dodson TB, Assael LA, Landesberg R, Marx RE, Mehrotra B; American Association of Oral and Maxillofacial Surgeons. American Association of Oral and Maxillofacial Surgeons position paper on bisphosphonate-related osteonecrosis of the jaws - 2009 update. J Oral Maxillofac Surg. 2009;67(Supp1 5):2-12.

2. Borromeo GL, Tsao CE, Darby IB, Ebeling PR. A review of the clinical implications of bisphosphonates in dentistry. Aust Dent J. 2011;56(1): 2-9.

3. Marx RE. Pamidronate (Aredia) and zoledronate (Zometa) induced avascular necrosis of the jaws: a growing epidemic. J Oral Maxillofac Surg. 2003;61(9):1115-1117.

4. Ruggiero SL, Fantasia J, Carlson E. Bisphosphonate-related osteonecrosis of the jaw: background and guidelines for diagnosis, staging and management. Oral Surg Oral Med Oral Pathol Oral Radiol Endod. 2006;102(4):433-441.

5. Fedele S, Porter SR, D'Aiuto F, et al. Nonexposed variant of bisphosphonate-associated osteonecrosis of the jaw: a case series. Am J Med. 2010;123(11):1060-1064.

6. O'Ryan FS, Khoury S, Liao W, et al. Intravenous bisphosphonate-related osteonecrosis of the jaw: bone scintigraphy as an early indicator. J Oral Maxillofac Surg. 2009;67(7):1363-1372.

7. Treister NS, Friedland B, Woo SB. Use of cone-beam computerized tomography for evaluation of bisphosphonate-associated osteonecrosis of the jaws. Oral Surg Oral Med Oral Pathol Oral Radiol Endod. 2010;109(5):753-764.

8. Chiandussi S, Biasotto M, Dore F, Cavalli F, Cova MA, Di Lenarda R. Clinical and diagnostic imaging of bisphosphonate-associated osteonecrosis of the jaws. Dentomaxillofac Radiol. 2006;35(4): 236-243. 
9. Ruggiero SL. Emerging concepts in the management and treatment of osteonecrosis of the jaw. Oral Maxillofac Surg Clin North Am. 2013;25(1):11-20, v.

10. Freiberger JJ, Padilla-Burgos R, McGraw T, et al. What is the role of hyperbaric oxygen in the management of bisphosphonate-related osteonecrosis of the jaw: a randomized controlled trial of hyperbaric oxygen as an adjunct to surgery and antibiotics. J Oral Maxillofac Surg. 2012;70(7):1573-1583.

11. Huth KC, Jakob FM, Saugel B, et al. Effect of ozone on oral cells compared with established antimicrobials. Eur J Oral Sci. 2006; 114(5):435-440.

12. Arita M, Nagayoshi M, Fukuizumi T, et al. Microbicidal efficacy of ozonated water against Candida albicans adhering to acrylic denture plates. Oral Microbiol Immunol. 2005;20(4):206-210.

13. Nagayoshi M, Fukuizumi T, Kitamura C, Yano J, Terashita M, Nishihara T. Efficacy of ozone on survival and permeability of oral microorganisms. Oral Microbiol Immunol. 2004;19(4):240-246.

14. Ebensberger U, Pohl Y, Filippi A. PCNA-expression of cementoblasts and fibroblasts on the root surface after extraoral rinsing for decontamination. Dent Traumatol. 2002;18(5):262-266.

15. Vescovi P, Nammour S. Bisphosphonate-Related Osteonecrosis of the Jaw (BRONJ) therapy. A critical review. Minerva Stomatol. 2010; 59(4):181-203, 204.

16. Black DM, Delmas PD, Eastell R, et al; HORIZON Pivotal Fracture Trial. Once-yearly zoledronic acid for treatment of postmenopausal osteoporosis. N Engl J Med. 2007;356(18):1809-1822.

17. Estilo CL, Van Poznak CH, Wiliams T, et al. Osteonecrosis of the maxilla and mandible in patients with advanced cancer treated with bisphosphonate therapy. Oncologist. 2008;13(8):911-920.

18. Bamias A, Kastritis E, Bamia C, et al. Osteonecrosis of the jaw in cancer after treatment with bisphosphonates: incidence and risk factors. J Clin Oncol. 2005;23(34):8580-8587.

19. Jadu F, Lee L, Pharoah M, Reece D, Wang L. A retrospective study assessing the incidence, risk factors and comorbidities of pamidronaterelated necrosis of the jaws in multiple myeloma patients. Ann Oncol. 2007;18(12):2015-2019.

20. Hoff AO, Toth BB, Altundag K, et al. Frequency and risk factors associated with osteonecrosis of the jaw in cancer patients treated with intravenous bisphosphonates. J Bone Miner Res. 2008;23(6): 826-836.
21. Dimopoulos MA, Kastritis E, Anagnostopoulos A, et al. Osteonecrosis of the jaw in patients with multiple myeloma treated with bisphosphonates: evidence of increased risk after treatment with zoledronic acid. Haematologica. 2006;91(7):968-971.

22. Ruggiero SL, Mehrotra B, Rosenberg TJ, Engroff SL. Osteonecrosis of the jaws associated with the use of bisphosphonates: a review of 63 cases. J Oral Maxillofac Surg. 2004;62(5):527-534.

23. Melo MD, Obeid G. Osteonecrosis of the jaws in patients with a history of receiving bisphosphonate therapy: strategies for prevention and early recognition. J Am Dent Assoc. 2005;136(12):1675-1681.

24. Yu XH, Yang YJ, Wang X, et al. [Effect of hyperbaric oxygenation on neural stem cells and myelin in neonatal rats with hypoxic-ischemic brain damage]. Zhongguo Dang Dai Er Ke Za Zhi. 2006;8(1):33-37. Chinese.

25. Thom SR, Bhopale VM, Velazquez OC, Goldstein LJ, Thom LH, Buerk DG. Stem cell mobilization by hyperbaric oxygen. Am J Physiol Heart Circ Physiol. 2006;290(4):H1378-H1386.

26. Gallagher KA, Goldstein LJ, Thom SR, Velazquez OC. Hyperbaric oxygen and bone marrow-derived endothelial progenitor cells in diabetic wound healing. Vascular. 2006;14(6):328-337.

27. Elayan IM, Axley MJ, Prasad PV, Ahlers ST, Auker CR. Effect of hyperbaric oxygen treatment on nitric oxide and oxygen free radicals in rat brain. J Neurophysiol. 2000;83(4):2022-2029.

28. Petrucci MT, Gallucci C, Agrillo A, Mustazza MC, Foà R. Role of ozone therapy in the treatment of osteonecrosis of the jaws in multiple myeloma patients. Haematologica. 2007;92(9):1289-1290.

29. Ramzy MI, Gomaa HE, Mostafa MI, BM Z. Management of aggressive periodontitis using ozonized water. Egypt Med JNRC. 2005;6:229-245.

30. Azarpazhooh A, Limeback H. The application of ozone in dentistry: a systematic review of literature. J Dent. 2008;36(2):104-116.

31. Gupta G, Mansi B. Ozone therapy in periodontics. J Med Life. 2012;5(1):59-67

32. Sarathy AP, Bourgeois SL, Goodell GG. Bisphosphonate-associated osteonecrosis of the jaws and endodontic treatment: two case reports. J Endod. 2005;31(10):759-763.
Therapeutics and Clinical Risk Management

\section{Publish your work in this journal}

Therapeutics and Clinical Risk Management is an international, peerreviewed journal of clinical therapeutics and risk management, focusing on concise rapid reporting of clinical studies in all therapeutic areas, outcomes, safety, and programs for the effective, safe, and sustained use of medicines. This journal is indexed on PubMed Central, CAS,

\section{Dovepress}

EMBase, Scopus and the Elsevier Bibliographic databases. The manuscript management system is completely online and includes a very quick and fair peer-review system, which is all easy to use. Visit http://www.dovepress.com/testimonials.php to read real quotes from published authors. 